Authors: Juan Llopis ${ }^{\mathrm{a},}{ }^{*}$, Jose Gasco ${ }^{\mathrm{a}}$ and Reyes Gonzalez ${ }^{\mathrm{a}}$

${ }^{a}$ Department of Business Organization. University of Alicante Campus San Vicente del Raspeig. P.O. Box. 99. 03080. Alicante (Spain)

* Corresponding author: Tel: 34 965903607; Fax: 34 965903606; E-mail address: juan.llopis@ua.es 
TRAINING CUSTOMERS: AN ORGANIZATIONAL EXPERIENCE

Keywords: Training Techniques, Training Customers, Customer-Oriented Culture, Spanish Firm

Article Type: Research and Case Study Paper

\begin{tabular}{|c|c|}
\hline Purpose of the paper & $\begin{array}{l}\text { Analyzing, through a case study, the essential } \\
\text { premises on the basis of which a training plan for } \\
\text { the customers of any given firm can be designed, } \\
\text { implemented and evaluated. }\end{array}$ \\
\hline $\begin{array}{l}\text { Design/methodology/approa } \\
\text { ch }\end{array}$ & $\begin{array}{l}\text { This paper starts with a review of the literature } \\
\text { on customer service training, which is followed } \\
\text { by a discussion on how a training plan for } \\
\text { customers could be elaborated. After that, the } \\
\text { case method is applied (mainly through semi- } \\
\text { structured interviews) to a firm that approaches } \\
\text { this type of training in an innovative way. }\end{array}$ \\
\hline Findings & $\begin{array}{l}\text { We conclude that a training plan for the firm's } \\
\text { internal staff cannot be extrapolated to } \\
\text { customers. Taking that into account, we have } \\
\text { described how training plans must be modified so } \\
\text { as to adapt them to customers. }\end{array}$ \\
\hline $\begin{array}{l}\text { Research } \\
\text { limitations/implications }\end{array}$ & $\begin{array}{l}\text { We will have to identify other cases and check to } \\
\text { what extent the methodology resembles the one } \\
\text { we have applied and how successful it is, so that } \\
\text { a standard action protocol can be established. }\end{array}$ \\
\hline Practical implications & $\begin{array}{l}\text { We present a real case of success at customer } \\
\text { training in an industrial firm. This paper can } \\
\text { provide a model, not only for future research, but } \\
\text { also for the direct implementation of these } \\
\text { techniques by other firms belonging to any } \\
\text { industrial sector. }\end{array}$ \\
\hline $\begin{array}{l}\text { What is original/value of the } \\
\text { paper }\end{array}$ & $\begin{array}{l}\text { The accurate description of a training plan for } \\
\text { customers made by an industrial firm and its } \\
\text { treatment based on the study of a real case. The } \\
\text { establishment of action guidelines that will pave } \\
\text { the way for further academic research in this } \\
\text { field as well as its clear business applicability. }\end{array}$ \\
\hline
\end{tabular}




\section{Training customers: An organizational experience ${ }^{1}$}

\section{Training employees for customer satisfaction and training customers directly}

It is obvious that the business world is currently going through a transformation process with changes that affect and are affected by the people who develop their professional activity at enterprises. In this respect, Minnick and Ireland (2005) point out that re-engineering, downsizing, outsourcing, structural transformation, acquisition, whatever the source, the changes are much more than a slow growth of something new. For employees adversely affected by these changes or for those who do not fully understand why these changes are occurring, the effects can be demoralizing, often creating ill-will or a lack of trust between workers and their employers.

Although we cannot deny the above, Foote (2004), following Delany and Huselid (1996), Dess and Shaw (2001), Huselid (1995) and MacDuffie (1995), said that positive associations also seem to exist between high performance, Human Resource Management (HRM) systems and organizational performance. The systems described involve a number of practices including extensive employee training, employee participation and empowerment, job redesign, team-based production systems and performance-contingent incentive compensation.

Of all the HRM practices mentioned above, this paper will focus mainly on training issues. In this sense, the variables around which an employee training plan is organized have been widely treated in the literature. Thus, for example, Korsten (2003) dealt with training myths and training plans, and

\footnotetext{
${ }^{1}$ The authors wish to thank everybody at the firm Jimten for their willingness and kindness throughout the development of the research work, particularly Santiago Giménez, the Managing Director, and Manuel Lozano, the Logistics and Personnel Department Manager. The Communications and Marketing Departments also collaborated in the ratification of previous working drafts.
} 
showed how to develop a training plan; Smith and Vaughan (1997) presented training as a strategic aspect; Dufficy (2001) specified the reasons for training, along with the benefits derived from it; Hashim (2001) analysed the practice of training evaluation; Lin and Darling (1997) described the requirements for success at training; Goldstein (1993) developed the different stages of training; Gainey and Klaas (2003) referred to the outsourcing of training; Noe (1999) explained how difficult it is to imitate other firms as far as training is concerned; Farrington (2003) introduced procurement training and development, and Burke (1997) forecasted that training would become a fundamental HRM technique in the future.

More specifically, the staff training meant to improve customer satisfaction has also been treated by both managers and academics. Thus, Burden and Proctor (2000), Innis and La Londe (1994), Landale (2004a), Mouawad and Kleiner (1996), Mulder (2001), Prager (2003), and Rosenthal, Hill and Peccei (1997), among others, have referred to issues like sales force training, raising employee awareness to meet customer needs, and the way in which customer satisfaction or "loyalty" toward the firm and its products can be improved.

We are not going to discuss the undeniable importance of customers and the ways in which they influence firm management schemes in this paper. We only want to remind that Barnard (1938) saw organizations as social systems that require human cooperation. Success depends on maintaining good relationships with people (here we can include customers) outside the organization with whom the organization regularly interacts.

Predisposition toward customer service leads to a business culture oriented to those customers, where firms try to strengthen a common value in which customers play a crucial role. From this perspective, Peccei and Rosenthal (2001) pointed out that management behavior, job design and values-based training can produce a sense of empowerment among employees, and the empowerment will generate pro-social customer-oriented behavior. The success of these programs is clearly likely to vary depending on a whole range of factors, including the nature of the program itself, its duration, and the combination of training and socialization mechanisms employed. Bowen (1986), Du Gay and Salaman (1992), Landale (2004b), 
Peccei and Rosenthal (2000), and Sturdy (2000) equally argue that training should be used to reinforce a customer-oriented culture.

Although specific training is undoubtedly important in order to achieve a customer-oriented culture (both in technical skills and in motivation), our aim in this paper is to go one step further in the field of training techniques: we are interested in training the actual customers, an idea that has hardly ever appeared in the literature so far. For instance, Thomke and von Hippel (2002) treated it in a very collateral way. They suggested five steps for turning customers into innovators: 1 . Developing a user-friendly tool kit for customers. 2. Increasing the flexibility of production processes. 3. Carefully selecting the first customers to use the tool kit. 4. Ensuring the continual, rapid evolution of the tool kit in order to satisfy leading-edge customers. 5. Adapting business practices accordingly.

Halbesleben and Buckley (2004) were closer to our objective when they developed the concept of "customer labor contribution", which refers to the role that customers play as human resources in service-based organizations. Their approach was based on Schneider and Bowen (1995), according to whom, in the case of customer labor contribution, the benefits are lower prices, greater satisfaction, greater speed, and greater customization.

In order to complement the above, we will have to take into account the contribution made by Goodwin (1988) when he claimed that the training of customers in customer labor contribution settings must focus not only on developing the knowledge, skills, and abilities necessary to engage in the labor contributions, but also on developing an identity with their new role as contributors to service through changing values so as to better fit those of the organization. This proposal to train customers with the purpose of improving their expectations and behaviors toward the firm was also made by Bateson (2002).

At this stage, we should highlight that the aim of this research paper is precisely to outline, through the study of a specific case, the main premises on the basis of which a training plan for customers can be designed, implemented and evaluated. More precisely, we have tried to analyze the peculiarities of this human group as far as training is concerned (it must be remembered that customers are not members of the firm and therefore do not own the same organizational culture) focusing on aspects such as the training place, the 
choice of participants (the number and their possible financing), the duration and timetable, the profile of trainers and the pedagogical method, to mention just a few of the most relevant issues.

It is also important not to confuse customer training with a mere commercial presentation. This should not only be understood by the firm that imparts training but also clearly perceived by the student-customer. This is why several departments are going to be involved in this training work, not only Marketing but also R\&D, Quality and, of course, Human Resources.

The research methodology we are going to use in order to achieve the objective we have set ourselves is the case method. Thus, we will firstly refer to the origins of the firm analyzed and its success, after which its innovative customer training experience will be described. Then, we will show how the customer training plan was implemented in that particular firm, and finally some conclusions drawn from this case study will be offered.

\section{The story of the development of a great idea}

In the early 1960s, Jimten, a small plumbing firm based in Alicante (a town located in Southeast Spain) and established by two brothers, was constantly expanding as a result of the construction boom in Spain. Jimten's business focused on setting up the plumbing of the new buildings that were built in Alicante and in the nearby coastal towns.

In few years, and despite its owners' young age, the firm began to stand out from its competitors, both by the quality and by the price of its work.

All the pieces installed at the time were made with lead. At present, these components can only be found in buildings erected over thirty years ago. Lead accessories and pipes had the inconvenience that they required highly specialized labor as well as a long time to be set up. As a result of this, the cost of the installation was substantial.

The two brothers had in mind creating a system that made it easier to install the plumbing. If they were successful, they could offer better prices and consequently increase their turnover; the market was not a problem, since the building sector growth seemed unstoppable. 
One of the founders had the idea of replacing lead with plastic going around in his head. Plastic is water-resistant and usually has a nearly unlimited duration. Why not putting pieces together by means of threads and joints instead of welding them? Thanks to this idea, that little firm was going to give work to 370 fixed employees, apart from creating another 80 indirect jobs, and was going to have an annual turnover of 52 million euros in 2005, all of which has placed it among the 250 largest Spanish firms.

Both the appearance and the later development of this idea were closely linked with the expansion of the toy sector firms in the Alicante province, as these firms pioneered the use of plastic injection technology.

Nowadays, Jimten is the Spanish market leader in its segment, even though many small firms are trying to follow in its steps, though with a much smaller number of employees, a much more reduced product range, and a less aggressive innovative policy.

In June 1993, Jimten was acquired by the Belgian group ETEX, a financial conglomerate that is present in all five continents and gives work to some 23,000 employees distributed in more than one hundred firms associated with the world of construction. Jimten's relationship with the ETEX group is far from being the typical parent-subsidiary relationship. This is proved by the fact that, at the beginning of each accounting year, the group's Board of Directors approves, with slight corrections, the business plan that is presented before it. Although Jimten must achieve the objectives proposed, it has financial and operational independence.

As far as the product range is concerned, components basically continue to be produced with the same purposes as when the firm was created. However, the development of plastic technology, the requirements of architects and the introduction of plastic in agriculture, particularly in the new systems of trickle irrigation and micro-irrigation, have favored product range enlargement. The catalogue currently includes over 3,500 references which can be grouped together in three 'families': drainage, building and pressure.

The main customers, both Spanish and foreign ones, are wholesalers who sell to plumbing professionals; in any case, national sales prevail with $85 \%$ of the total. On the other hand, none of the customers alone accounts for more than $5 \%$ of the total sales. 
As far as competitors are concerned, Jimten is undoubtedly the top manufacturer in Spain. However, like any other relatively new product, it has attracted many people with an enterprising spirit. Since there are no great entry barriers to the business, new firms specialized in plastic injection technology are entering this sector. On the other hand, some factories manufacture their own moulds and outsource the plastic injection process as well as the setting-up to small firms which develop similar activities for leading toy brands in the Alicante province.

The main inconvenience these competitors must face is having to invest in moulds; for example, the last collection of moulds meant an investment of nearly one million euros, a figure that is completely out of reach for small businesses. This is why the field of action of these small firms focuses on manufacturing specific products that have already been present in the market for some time instead of complete ranges; i.e. products that logically provide less added value.

Jimten is the first firm in its segment to achieve the ISO 9002 and ISO 14001 certifications. In fact, if it manages to maintain its current product quality level, pays attention to the rate of innovation in new components, and is able to keep customer loyalty, Jimten's success will most probably continue for long.

The organizational structure has not suffered significant changes during the last fifteen years, not even after the firm was sold to the ETEX group. In the early years, Jimten, like most of the family firms which expand, had a centralized management closely associated with the leadership transmitted by its founders. From the very beginning, the two founding brothers shared the managerial responsibilities: one of them was in charge of the technicaladministrative area, and the other managed the commercial area. As the firm grew, other young executives joined the organization, and the founders slowly but steadily delegated responsibilities to them. The fact that the newly arrived were people with a high technical qualification but little managerial experience, along with the enterprising spirit of the two founders, helped to create a united team characterized by the excellent personal relationships and the strong motivation to achieve innovation and quality.

\section{An innovative experience: quality through customer training}


Although, as we said above, the firm is certified in ISO 9002 and ISO 14001 , Jimten is perfectly aware that the certification is not a mere marketing instrument; in fact, it has meant a considerable improvement in the general functioning of the firm. However, the managers know that the efforts they have been making so far do not suffice to ensure that the end user of the products (the average citizen) will fully enjoy their quality, since wholesalers and installers are also an important link in the value chain of the firm's products (as can be seen in Figure 1).

Figure 1: Jimten's value chain

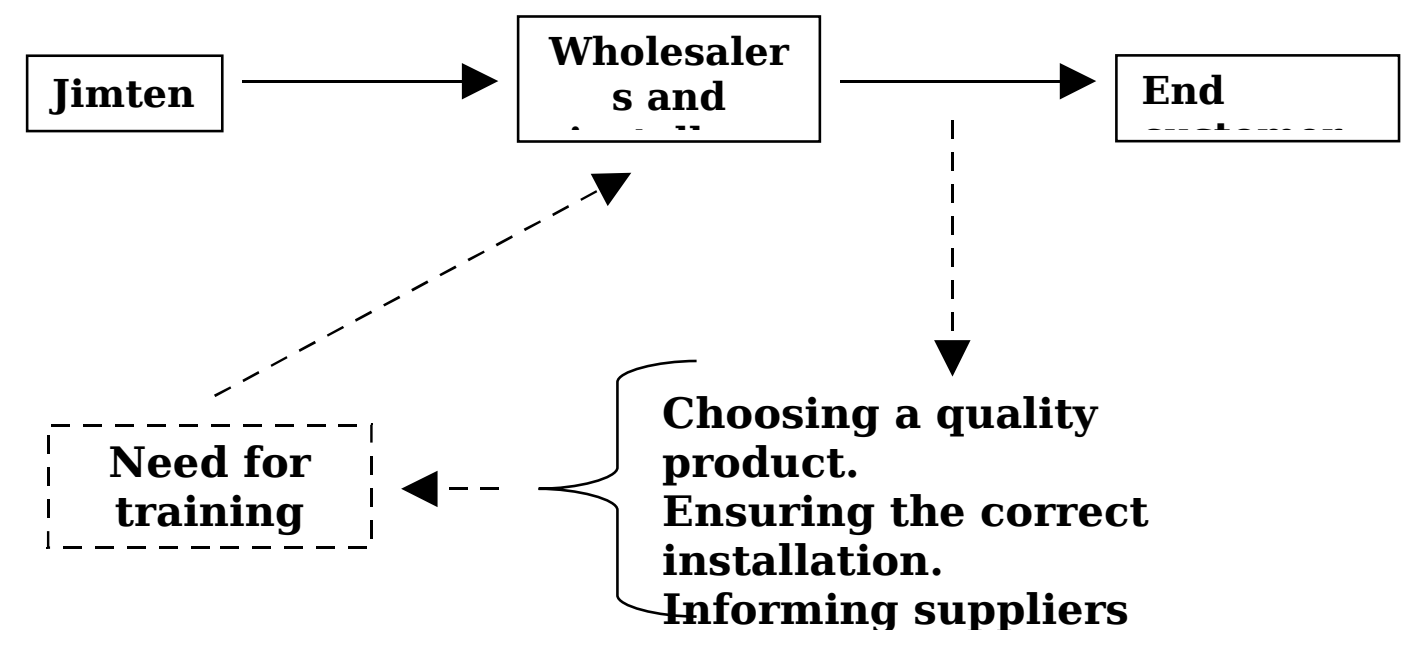

Developing Figure 1, the firm can be said to face three problems: in the first place, some wholesalers tempted by competitors' cheaper prices offer installers products of other brands which, despite being lower-quality, often have more attractive prices. This is why it would be interesting that both wholesalers and installers should recognize the higher quality and innovative character of Jimten products.

On the other hand, the success achieved by some of the most complex products manufactured depends on their correct installation; a faulty installation may prevent the end user from appreciating product quality. 
Finally, it must be remembered that this firm arose and developed thanks to the initiative of two plumbers who knew the needs of these professionals perfectly. For that reason, the awareness exists that being permanently informed about the real needs of the sector turns out to be essential so that the innovation process does not stop.

Due to all the above, a bold, determined action on the part of the management that could face and solve these three problems would be an important complement to consolidate the firm's leadership through quality.

Until a relatively short time ago, training activities had sporadically been organized with the aim of finding solutions to the three problems mentioned above. Nevertheless, the management knew that those activities had to be formalized, enlarged and improved; in other words, they had to design a training plan, not for their employees, but for the customers and users of the firm's products. It was believed that the training plan should achieve the following goals:

- Ensuring that wholesalers and installers recognize the higher quality of the firm's products as opposed to those offered by competitors.

- Making sure that products are used and installed properly.

- Seeing that the people responsible for new product creation and development receive as many suggestions as possible about the products from product users.

The idea was not considering it an isolated, independent plan that had nothing to do with the other plans of the firm, but as an instrument linked with the whole organizational policy (particularly in the areas of quality and innovation) meant to consolidate the firm's leading position in the market and to increase user satisfaction levels as well.

This is how the "Taller Escuela de Jimten" (TEJ) -Jimten's WorkshopSchool- was born in 1990 as a response to the need for training of professionals in this sector associated with a project that the firm had developed to introduce a new technical product into the market. The product represents a true innovation in the field of installations, but its good qualities can become useless if there are no professionals who can use it properly. 
Sessions with groups of installers started to be held in which they were trained in the correct use of some specific plastic tube systems suitable for heating sanitary hot water installations that provided a solution to the problems of traditional installations, which corroded or got blocked with lime.

From then on, other possibilities for workshop activities have been observed, some of which have materialized in initiatives like the following:

- School for the installation of new materials.

- Presentation workshop for Jimten's innovations.

- A forum where the actual installers can express critical opinions or comments and make suggestions about the manufactured products, all of which will largely help to improve those products.

- Presentations addressed to technical associations and professional bodies.

- Talks with students and firm customer commercial teams.

This idea did not originate in Jimten. In fact, when the initiative was set in motion, the firm knew of other firms in the same sector that were already applying this strategy. The difference lies in the fact that, whereas the reference firm's application is still confined to the initial use, Jimten has largely widened the spectrum of actions contemplated within this scheme.

On the other hand, the decisions made in relation to the issues listed below are also very important:

- The students (firm customers) must be selected very carefully; an adequate selection boosts and favors the success of any training activity.

- Those who take part in a training program like this cannot be mere spectators. Without the active collaboration of participants, the training activity would be much less effective.

- Those in charge of training actions need the collaboration of participants for the development of objectives.

- The contents imparted must meet the professional needs of those who take part in the training actions.

- The training activities must meet the firm's needs; the program proposed must provide solutions to the problems from which the training needs diagnosed derive. 
- The training materials that are elaborated and supplied must have a value of their own and be a high-quality information source for participants.

- The contents must be adapted to the addressees, with an accessible language that facilitates comprehension.

- Support materials must allow participants to deepen their knowledge and understanding in a later stage.

- It is advisable to establish systems or methods to assess the extent to which the results of training improve firm performance.

More specifically, the doubts that precede the development of a training plan for firm customers materialize in the following questions:

- Are course addressees aware of their training needs? If that is the case, how intensely do they perceive those needs?

- How can the specific training needs be determined? What mechanism should be used in order to know the participants' current level of knowledge?

- What are the motivations and expectations of potential students?

- Is there a way to quantify the objectives?

- Are the objectives related to one another? Can one objective be achieved individually without taking the others into account?

\section{The implementation of the training plan for the firm's customers}

Bearing in mind all the issues mentioned above, the content of the training plan was structured in three blocks: in the first one, an attempt was made to fidelize students with the brand. The second one focused on the participants' acquisition of knowledge about new products (or technologies that were not present in the market) and about the correct installation of the most complex products. The third block had as its main aim to channel students' doubts, clarifications and suggestions to improve the products.

In short, it can be said that the objective sought is to make sure that the calculation techniques, the installation procedures, and the characteristics of 
the new products are known to the market, as this will permit their effective commercialization.

Based on these premises, Jimten designed its customer training plan, in which special attention was paid to the following aspects:

a) Training place.

b) Selection of students (customers).

c) Limitation of the number of students (customers) and their financing.

d) Duration and timetable.

e) Training Staff.

f) Pedagogical method.

g) Training evaluation.

a) Regarding the training place, the firm initially decided to impart the training in its own premises and not in an itinerant way, i.e. going from one town to another, for the following reasons:

- The student is not likely to have interruptions and, in principle, will attend all the classes.

- If the training is always imparted in the same place, trainers will feel more at ease and will consequently improve their ability to transmit ideas.

- Teachers do not need to travel and therefore can assume other responsibilities at the same time.

- It is easier to organize timetables as well as changing them if necessary.

- Using the pedagogical means becomes easier too.

- Students have physical contact with the business premises, thanks to which the image they acquire will be a more lasting one.

- Student motivation can increase if the training period is combined with fun activities (the Alicante province has great tourist appeal).

Despite these advantages, Jimten perfectly knows that this decision entails inconveniences too. For example, students must leave their city and neglect their personal and professional duties. Besides, the expenses corresponding to the food, accommodation and transport of all the students exceed the cost of taking the teaching staff elsewhere. In this way, the TEJ can currently make presentations at the headquarters of Professional Bodies, 
at university classrooms, customer facilities or conference rooms. The concept of adaptability is being gradually introduced, above all if partial events (fairs, conventions...) take place in areas where important or potential customers reside.

b) Another point to consider is who should the students be; the dilemma here is, should they be the wholesalers (the customers) or the installers (the customers' customers)? If wholesalers were the chosen ones, the second and third objective would be very difficult to achieve, as they do not install the products and consequently do not know what changes or improvements are required. On the other hand, we must highlight that wholesalers exert a strong influence on installers when it comes to choosing one brand or another. The firm finally opted for a mixed solution in which wholesalers would attend the courses together with some of the installers in their area that they had selected themselves. After all, wholesalers are the ones who know installers best. Similarly, students are also selected according to the field on which training is going to focus. Thus, if it is new products or installation procedures, the students are usually technicians or installers. If the aim is indepth product knowledge with the purpose of giving advice, they tend to be salesmen belonging to customer commercial networks. Finally, if the objective is to show technical characteristics that distinguish them from other products, visits are usually paid to engineering firms, top installers or architects.

c) One more aspect to think about is whether or not it would be advisable to limit the number of customers and if to finance the expenses. The solution proposed was to carry out a geographical rotation of customers (for example, organizing the course for those of them who live in a particular town) and finance the travel, accommodation and food expenses (but no salaries at all). Time has shown that it was a very good proposal. In fact, many customer firms even contribute financially to the implementation of the training program agreed with them.

d) Regarding duration and timetable, a day and a half was established as the habitual duration of the training sessions. We are not talking about providing the students with technical qualifications, because they already have them; what we are trying to do is highlight the possibilities of the new products. Sometimes, the training is complemented with an external activity that consists in a visit to Benidorm (an important tourist resort) with dinner 
and show included. In this respect, we must not forget that these people are students attending a training course, but also customers, and both aspects must be taken care of.

In addition to the above, we should explain that the plan is flexible, but a proposal for an all-year-round calendar is prepared depending on the needs identified, along with a budget that must be approved and has a monthly follow-up.

e) As for the staff who impart the training, the choice made was very clear from the very beginning: using internal staff and rejecting external consultants as a general rule. The firm had to give training to trainers because, although the technical part was covered, the area corresponding to the pedagogical method was not. The course has always focused on the practical side rather than on aspects like engineering and besides, it has never been approached as a mere commercial presentation; after all, the firm has other advertising channels available to do that. Therefore, the firm chooses a person who is responsible for this function and usually presents a plan outlined by the firm's experts. Nevertheless, when the situation requires it, the communications are made by the technicians themselves or by product managers who are usually experts with university degrees.

f) Concerning the pedagogical method, the first part of the course starts with a lecture; an effort is made to make a preliminary presentation of the firm in one hour. The message is accompanied by slides, pictures, illustrative objects and so on. All participants attend this presentation, which is followed by a visit to the premises in groups of 10 to 15 people (it must be remembered that the size of an average TEJ course group is between 25 and 40 students).

In the second module, demonstrations are carried out about the correct installation of the most complex products, while the third module focuses on organizing debates chaired by Marketing, $R \& D$ and Quality Managers in which students can ask questions and make suggestions.

In short, we can actually say that, depending on the function of the products and on how well-known they are in the market, the firm uses talks, presentations with samples, product discussion meetings and practical installation sessions.

g) With respect to training evaluation, a questionnaire is delivered to the participants at the end of each course, in which they can give their opinion 
about the course. Anyway, for the time being, the firm finds it very difficult to quantify the effect of this training on sales. It is indeed true that, although the existence of a direct cause-effect relationship cannot be proved, sales have increased since the TEJ opened its doors. Furthermore, this training plan has proved to be a very effective tool in order to achieve a much closer relationship with customers.

\section{Conclusions}

The variables on which a training plan for employees is based have been widely treated in the literature and so has been the training of employees to improve customer satisfaction. However, the idea of training the customers themselves represents a great step forward in the field of training techniques.

From this point of view, this paper has precisely as its main aim to outline, through the study of a specific case, the main premises on the basis of which a training plan for customers can be designed, implemented and evaluated. More precisely, we have tried to analyze the peculiarities of this human group as far as training is concerned (it must be remembered that they are not members of the firm and consequently do not own the same organizational culture) for which we focused on aspects like the training place, the selection of the participants (the number and their possible financing), the duration and timetable, the profile of trainers, the pedagogical method and the evaluation of the training, to mention just a few of the most relevant issues.

It is equally essential not to confuse customer training with a mere commercial presentation. This must not only be assumed by the firm that imparts the training, but also be clearly perceived by the students-customers themselves. This is why several departments are going to become involved in this training, not only Marketing, but also R\&D, Quality and, of course, Human Resources.

In the specific case presented in this paper, the benefits for the firm have been outstanding; more precisely, the products and the firm became more well known to customers, people were taught to use the firm's products 
properly, new users were identified (the firm knew the wholesalers, but not many installers) and finally, suggestions and ideas were received to improve or create new products. The truth is that, although the firm admits that customer training used to have a reactive character when it started being implemented, nowadays, after the accumulated experience and the reality of the introduction of new technologies in relation to materials, the customers' need for training has become proactive, since an attempt is made to anticipate problems and solve them before they arise.

All these benefits will be obtained by any firm that treats this type of training with the same rigor, or even more, than it treats employee training. Although a successful reality has been described in this case, it would be interesting to analyze other cases as well as other academic and professional reflections, as this would help to outline a customer training plan protocol.

To sum up, we conclude that a training plan for the firm's internal staff cannot be extrapolated to customers, since, although they are all students, customers are special students insofar as they do not belong to the firm. This is why customers obviously have to be treated in a different way. Future research works in this field will be required in order to establish monitoring guidelines. In this case, we think that the contribution made by the organization we have dealt with is definitely enriching, as can be evidenced in the lines appearing on the firm's web page (http://www.jimten.com): "The function of the Taller Escuela de Jimten consists in keeping professionals in the sector -like installers, master builders and architects- informed and training them... We have imparted one- or two-day long courses, in which over 5,000 professionals were trained. The Taller Escuela de Jimten tries to transmit the new trends in products, and shows new ways to install and use Jimten products". 


\section{References}

Barnard, C.I. (1938), The functions of the executive, Harvard University Press, Cambridge, MA.

Bateson, J. (2002), "Are your customers good enough for your service business?", Academy of Management Executive, Vol. 16, No. 4, pp. 110-121.

Bowen, D.E. (1986), "Managing customers as human resources in service organizations", Human Resource Management, Vol. 25, No. 3, pp. 371-383.

Burden, R. and Proctor, T. (2000), "Creating a sustainable competitive advantage through training", Team Performance Management: An International Journal, Vol. 6, No. 5/6, pp. 90-96.

Burke, W.W. (1997), "What human resource practitioners need to know for the twenty-first century", Human Resource Management, Vol. 36, No. 1, pp. 7179.

Delany, J.T. and Huselid, M.A. (1996), "The impact of human resource management practices on perceptions of organizational performance", Academy of Management Journal, Vol. 39, No. 4, pp. 949-969.

Dess, G.G. and Shaw, J.D. (2001), "Voluntary turnover, social capital, and organizational performance", Academy of Management Review, Vol. 26, No. 3, pp. 446-456.

Du Gay, P. and Salaman, G. (1992), "The cult(ure) of the customer", Journal of Management Studies, Vol. 29, No. 5, pp. 615-633.

Dufficy, M. (2001), "Training for success in a new industrial world", Industrial and Commercial Training, Vol. 33. No. 2, pp. 48-53.

Farrington, B. (2003), "Action-centred learning", Industrial and Commercial Training, Vol. 35, No. 3, pp. 112-118.

Foote, D.A. (2004), “Temporary workers. Managing the problem of unscheduled turnover", Management Decision, Vol. 42, No. 8, pp. 963-973.

Gainey, T.W. and Klaas, B.S. (2003), "The outsourcing of training and development: Factors impacting client satisfaction", Journal of Management, Vol. 29, No. 2, pp. 207-229.

Goldstein, I. (1993), Training in Organizations, Brooks-Cole, Pacific Grove, CA.

Goodwin, C. (1988), "I can do it myself: Training the service consumer to contribute to service productivity", Journal of Services Marketing, Vol. 2, No. 4 , pp.71-78. 
Halbesleben, J.R.B. and Buckley, M.R. (2004), "Managing customers as employees of the firm. New challenges for human resource management", Personnel Review, Vol. 33, No. 3, pp. 351-372.

Hashim, J. (2001), "Training evaluation: client's roles", Journal of European Industrial Training, Vol. 25, No. 7, pp. 374-379.

Huselid, M.A. (1995), "The impact of human resource management practices on turnover, productivity, and corporate financial performance", Academy of Management Journal, Vol. 38, No. 3, pp. 635-670.

Innis, D.E. and La Londe, B.J. (1994), "Customer service: The key to customer satisfaction, customer loyalty, and market share", Journal of Business Logistics, Vol. 15, No. 1, pp. 1-27.

Korsten, A.D. (2003), "Developing a training plan to ensure employees keep up with the dynamics of facility management", Journal of Facilities Management, Vol. 1, No. 4, pp. 365-379.

Landale, A. (2004a), "Sales training bags the results for Cleanaway", Industrial and Commercial Training, Vol. 36, No. 5, pp. 216-218.

Landale, A. (2004b), "Get close, stay close", Industrial and Commercial Training, Vol. 36, No. 1, pp. 35-37.

Lin, B. and Darling, J. (1997), "A processual analysis of customer service training", Journal of Services Marketing, Vol. 11, No. 3, pp. 193-205.

MacDuffie, J.P. (1995), "Human resource bundles and manufacturing performance: Flexible production systems in the world auto industry", Industrial and Labor Relations Review, Vol. 48, No. 2, pp. 197-221.

Minnick, D.J. and Ireland, R.D. (2005), "Inside the new organization: A blueprint for surviving restructuring, downsizing, acquisitions and outsourcing", Journal of Business Strategy, Vol. 26, No. 1, pp. 18-25.

Mouawad, M. and Kleiner, B.H. (1996), "New developments in customer service training", Managing Service Quality, Vol. 6. No. 2, pp. 49-56.

Mulder, M. (2001), "Customer satisfaction with training programs", Journal of European Industrial Training, Vol. 25, No. 6, pp. 321-331.

Noe, R. (1999), Employee training and development, Irwin/McGraw Hill, Burr Ridge, IL.

Peccei, R. and Rosenthal, P. (2000), “Front-line responses to customer orientation programs: A theoretical and empirical analysis, International Journal of Human Resource Management, Vol. 11, No. 3, pp. 562-590. 
Peccei, R. and Rosenthal, P. (2001), "Delivering customer-oriented behavior through empowerment: An empirical test of HRM assumptions", Journal of Management Studies, Vol. 38, No. 6, pp. 831-857.

Prager, H. (2003), "Gaining a competitive advantage through customer service training", Industrial and Commercial Training, Vol. 35, No. 6, pp. 259-262.

Rosenthal, P., Hill, S. and Peccei, R. (1997), "Checking out service: Evaluating excellence, HRM and TQM in Retailing", Work, Employment and Society, Vol. 11, No. 3, pp. 481-503.

Schneider, B. and Bowen, D.E. (1995), Winning the service game, Harvard Business School Press, Boston, MA.

Smith, D. and Vaughan, S. (1997), "The outdoors as an environment for learning and change management", Industrial and Commercial Training, Vol. 29, No. 1, pp. 26-30.

Sturdy, A. (2000), "Training in service. Importing and imparting customer service culture as an interactive process", International Journal of Human Resource Management, Vol. 11, No. 6, pp. 1082-1103.

Thomke, S. and von Hippel, E. (2002), "Customers as innovators. A new way to create value", Harvard Business Review, Vol. 80, No. 4, pp. 74-81. 